\title{
Was the Military Operation "Protective Edge" a Risk Factor for Pregnancy Complications?
}

\author{
Ohad Gluck, M.D.*, Yossi Mizrachi, M.D., Sophia Leytes, M.D., Jacob Bar, \\ M.D., and Michal Kovo, M.D. \\ Department of Obstetrics and Gynecology, E. Wolfson Medical Center, Holon, Israel, and Sackler School \\ of Medicine, Tel Aviv University, Tel Aviv, Israel
}

\begin{abstract}
Objective: During July-August 2014, the military operation "Protective Edge" presented Israel with a threat of missile attacks. We aimed to investigate the influence of the "Protective Edge" operation on the rate of pregnancy complications among the population exposed to missile attacks, compared to the population not exposed.
\end{abstract}

Study Design: This was a retrospective study. Pregnancy outcomes were compared between women who during pregnancy were exposed to the stress of the military operation (exposed group, $n=4,673$ ) and gave birth at the Wolfson Medical Center, and women who gave birth in the previous year (unexposed group, $n=4,735)$.

Results: Rates of pregnancy complications did not differ between the groups.

Conclusion: Exposure to environmental stress during pregnancy, for a period of almost two months, was not found to be associated with increased risk for pregnancy complications.

KEY WORDS: Mental stress, pregnancy complications, preterm labor

\footnotetext{
Abbreviations: BMI, body mass index; GA, gestational age; HPA, hypothalamic-pituitary-adrenal; IUFD, intrauterine fetal demise; IUGR, intrauterine growth restriction.

Citation: Gluck O, Mizrachi Y, Leytes S, Bar J, Kovo M. Was the Military Operation "Protective Edge" a Risk Factor for Pregnancy Complications?. Rambam Maimonides Med J 2017;8 (2):e0027. doi:10.5041/RMMJ.10304

Copyright: (C) 2017 Gluck et al. This is an open-access article. All its content, except where otherwise noted, is distributed under the terms of the Creative Commons Attribution License (http://creativecommons.org/licenses/by/3.0), which permits unrestricted use, distribution, and reproduction in any medium, provided the original work is properly cited.

Conflict of interest: No potential conflict of interest relevant to this article was reported.

* To whom correspondence should be addressed. E-mail: ohadgluck@gmail.com
} 


\section{INTRODUCTION}

Maternal stress during pregnancy has been associated with adverse birth and pregnancy outcomes. Studies have demonstrated an association between maternal mental stress during pregnancy and pregnancy complications, including low birth-weight, preterm delivery, and preeclampsia, especially among highly exposed women. ${ }^{1-5}$

Several mechanisms have been proposed for explaining this association, and the most widely accepted theory is based on the hypothalamicpituitary-adrenal (HPA) axis response to stress. The activation of the HPA axis, as part of the stress mechanism, leads to an increased secretion of cortisol and catecholamines, which results in blood pressure elevation, blood glucose levels rising, and continuous oxidative stress. 3

Furthermore, during pregnancy there is a gradual increase in cortisol level, and it peaks before delivery. Chronic stress during pregnancy may elevate blood cortisol level prematurely, and by that lead to preterm delivery. In addition, catecholamine secretion, as a response to stress, may induce preterm contractions, which could lead to preterm delivery. ${ }^{6}$

The influence of military conflicts on pregnant women has been studied on several occasions in the past: studies of the prenatal stress during the 1999 bombing in Belgrade and the armed conflict of 2011 in Libya demonstrated a significant rise in the rate of preterm deliveries, low-birth-weight infants, and cesarean sections. The authors of both studies concluded that psychosocial stress during pregnancy might cause negative pregnancy outcomes. ${ }^{2,7}$ Wainstock et al. demonstrated a higher rate of preterm deliveries among Israeli women residing close to the Gaza strip who as a consequence were constantly exposed to rocket attack during pregnancy. 4

In July 2014 the military operation "Protective Edge" was launched by Israel in order to stop rocket attacks, which were targeting Israeli civilians. ${ }^{8}$ During the 51 days of the conflict (from July 7 to August 26,2014 ), terrorist organizations fired thousands of rockets and mortars at Israel's civilian population, at ranges that threatened most of the country. ${ }^{9}$ As detailed later, the rocket attacks were preceded by loud, sudden, and stress-inducing sirens, informing residents to seek shelter within only a few seconds before rockets hit the town. More than 4,600 sirens were sounded during 51 days of conflict, with an average of about 90 sirens per day.
The conflict led to a dramatic increase in the rate of mental health disorders, including anxiety, posttraumatic stress disorders (PTSD), depression, and other psychiatric disorders. ${ }^{10}$

The unfortunate situation in Israel during JulyAugust 2014 has presented an opportunity: our aim was to study the association between exposure to stress during pregnancy and poor pregnancy outcome.

\section{MATERIAL AND METHODS}

This was a retrospective, population-based, study. We reviewed the pregnancy outcome of all patients who during pregnancy were exposed to the stress of the military operation and delivered at the Wolfson Medical Center between July 7, 2014 and April 30, 2015-the exposed group. This medical center is in the city of Holon (in the center of Israel), and is about 70 kilometers from the Gaza strip. During the "Protective Edge" operation this region was attacked by population-targeted missiles, for the first time in its history, almost on a daily basis. During this period of time all the people in this area had to run into a shelter, in less than 30 seconds, when the alarm sounded. They were also exposed to explosive sounds and direct rockets hits. Even though most civilians were not physically hit, they suffered from constant anxiety and had abrupt stress attacks. We compared the exposed population in this area to an unexposed population: all women who delivered at the Wolfson Medical Center in the same calendar period of the year before (between July 7, 2013 and April 30, 2014); this group was defined as the unexposed group.

The medical records of all participants were retrieved from the computerized database. We reviewed maternal characteristics: age, body mass index (BMI), and parity. We checked if pregnancy was spontaneous or by assisted reproductive treatment and if it was single or multiple gestation. The following were also compared: mean gestational age (GA) at delivery and the mode of delivery; maternal chronic diseases (chronic hypertension and pregestational diabetes mellitus); pregnancy complications (early or late preterm delivery, defined as delivering before 34 or 37 complete weeks of gestation, respectively); gestational hypertensive disorders (which included eclampsia, preeclampsia, and pregnancy-induced hypertension); gestational diabetes mellitus; neonatal outcome and complications (birth-weight in grams, intrauterine growth restriction [IUGR], and intrauterine fetal demise [IUFD]). 
Chronic hypertension and gestational hypertensive disorders were diagnosed according to the American College of Obstetrics and Gynecology recommendations. ${ }^{11}$ Gestational diabetes mellitus was diagnosed when a 100-g oral glucose tolerance test (OGTT) resulted in two or more pathological values, after 24 weeks of gestation. Intrauterine growth restriction was defined as birth-weight less than the 1oth percentile, according to national birth-weight curves (Dolberg's birth-weight standards).

Data were analyzed by SPSS software, version 23 (IBM, Inc.). Continuous data were compared by Student's $t$ test, and categorical data were compared by chi-square test or by Fisher's exact test, as appropriate. Multivariate logistic regression was performed to adjust for potential confounders. A $P$ value of $<0.05$ was considered statistically significant. The study was approved by the local Institutional Review Board.

\section{RESULTS}

There were 4,673 women who were pregnant during the "Protective Edge" operation and delivered at the Wolfson Medical Center (exposed group), and 4,735 women who delivered in the previous year, at the same medical center (unexposed group). Compared to the unexposed group, the exposed women were slightly older $(30.2 \pm 6.2$ years versus $29.9 \pm 6.2$ years, respectively; $P=0.027$ ), and had a lower rate of nulliparity (33.0\% versus $36.0 \%$, respectively; $P=0.002$ ). They also had higher rate of chronic hypertension (o.8\% versus $0.1 \%$, respectively; $P<0.001$ ), pregestational diabetes mellitus (1.9\% versus $0.3 \%$, respectively; $P<0.001)$, and multiple gestation $(4.3 \%$ versus $2.3 \%$, respectively; $P<0.001)$. The mean BMI was not significantly different between the groups. Table 1 presents maternal and pregnancy characteristics.

Rates of pregnancy complications did not differ between the groups, including gestational hypertensive disorders, gestational diabetes mellitus, early or late preterm delivery, IUGR, and IUFD. Table 2 presents pregnancy complications.

Regarding delivery outcome, we found a lower rate of vacuum extraction among the exposed women ( $4.1 \%$ versus $5 \%$, respectively; $P=0.02$ ), but no differences in rates of normal deliveries or cesarean sections. There were also no differences between groups in rates of spontaneous deliveries or delivery
Table 1. Maternal and Pregnancy Characteristics.

\begin{tabular}{lcccc|}
\hline & $\begin{array}{c}\text { Unexposed } \\
(n=4735)\end{array}$ & $\begin{array}{c}\text { Exposed } \\
(n=4673)\end{array}$ & $\begin{array}{c}P \\
\text { Value }\end{array}$ \\
\hline Maternal age & $29.9 \pm 6.2$ & $30.2 \pm 6.2$ & 0.027 \\
BMI & $23.4 \pm 4.5$ & $23.4 \pm 4.5$ & 0.98 \\
Nulliparity & $1703(36.0)$ & $1541(33.0)$ & 0.002 \\
Multiple gestation & $110(2.3)$ & $201(4.3)$ & $<0.001$ \\
Chronic HTN & $6(0.1)$ & $36(0.8)$ & $<0.001$ \\
DM & $15(0.3)$ & $89(1.9)$ & $<0.001$ \\
\hline
\end{tabular}

Data are presented as $n(\%)$ or mean \pm SD.

BMI, body mass index; DM, diabetes mellitus; HTN, hypertension.

Table 2. Pregnancy Complications.

\begin{tabular}{|l|c|c|c|}
\hline & $\begin{array}{c}\text { Unexposed } \\
(n=4735)\end{array}$ & $\begin{array}{c}\text { Exposed } \\
(n=4673)\end{array}$ & $\begin{array}{c}P \\
\text { Value }\end{array}$ \\
\hline GHTN & $112(2.4)$ & $133(2.8)$ & 0.143 \\
GDM & $241(5.1)$ & $276(5.9)$ & 0.082 \\
Deliveries <37 weeks & $321(6.8)$ & $320(6.8)$ & 0.89 \\
Deliveries <34 weeks & $80(1.7)$ & $79(1.7)$ & 0.99 \\
IUGR $(<10 \%)$ & $321(6.94)$ & $343(7.5)$ & 0.3 \\
IUFD & $15(0.3)$ & $21(0.4)$ & 0.29 \\
\hline
\end{tabular}

Data are presented as $n(\%)$.

GDM, gestational diabetes mellitus; GHTN, gestational hypertensive disorders; IUFD, intrauterine fetal demise; IUGR, intrauterine growth restriction.

inductions, and mean gestational age at delivery. Table 3 presents delivery outcomes.

A higher percentage of male newborns was demonstrated in the exposed group (49.27\% versus $45.96 \%$, respectively; $P=0.001)$. Other neonatal outcomes did not significantly differ between groups, including mean birth-weight, rate of fetal macrosomia (birth-weight of more than 4,000 g), and low birth-weight (less than 2,500 g). Table 4 presents neonatal outcomes.

Subgroup analyses according to the fetus's gender, and according to gestational age (first, second, or third trimester) at the time of exposure to stress, have failed to reveal further differences between the groups in rates of pregnancy complications. 
Table 3. Delivery Outcomes.

\begin{tabular}{|l|c|c|c|}
\hline & $\begin{array}{c}\text { Unexposed } \\
(\boldsymbol{n}=4735)\end{array}$ & $\begin{array}{c}\text { Exposed } \\
(\boldsymbol{n}=4673)\end{array}$ & $P$ Value \\
\hline Mean GA at delivery (weeks) & $39.2 \pm 2.1$ & $39.2 \pm 2.2$ & 0.24 \\
Normal vaginal delivery & $3518(74.3)$ & $3507(75.0)$ & 0.4 \\
Vacuum extraction & $239(5.0)$ & $190(4.1)$ & 0.02 \\
Cesarean section & $978(20.7)$ & $976(20.9)$ & 0.78 \\
Spontaneous onset of delivery & $3404(72.6)$ & $3275(70.1)$ & 0.06 \\
Induction of labor & $739(15.8)$ & $786(16.8)$ & 0.11 \\
\hline
\end{tabular}

Data are presented as $n(\%)$ or mean \pm SD.

$\mathrm{GA}$, gestational age.

Table 4. Neonatal Outcomes.

\begin{tabular}{|l|c|c|c|}
\hline & $\begin{array}{c}\text { Unexposed } \\
(\boldsymbol{n}=4735)\end{array}$ & $\begin{array}{c}\text { Exposed } \\
(\boldsymbol{n}=4673)\end{array}$ & $\boldsymbol{P}$ Value \\
\hline Neonatal weight, g & $3222 \pm 518$ & $3228 \pm 524$ & 0.61 \\
Neonatal male gender & $2228(45.96)$ & $2402(49.27)$ & 0.001 \\
Neonatal weight $\geq 4000 \mathrm{~g}$ & $236(4.86)$ & $246(5.04)$ & 0.53 \\
Neonatal weight $\leq 2500 \mathrm{~g}$ & $108(2.22)$ & $98(2.01)$ & 0.54 \\
\hline
\end{tabular}

Data are presented as $n(\%)$ or mean \pm SD.

\section{DISCUSSION}

In contrast to ours, previous studies investigating the obstetrical implications of armed conflict have found an association between mental stress during pregnancy and pregnancy complications. ${ }^{2,4,7}$ Bodalal et al. compared deliveries during the 2011 armed conflict in Libya to deliveries that preceded it, and found higher rates of preterm deliveries, cesarean sections, and low birth-weight (less than 2,500 g).7 These findings are partially contradicted by Maric et al. who studied the pregnancy outcomes among women who were exposed to the 1999 bombing in Serbia. Although that study demonstrated lower birth-weight (by $86 \mathrm{~g}$ ) among exposed women, it also showed lower rates of cesarean sections, and no differences in rates of preterm deliveries or other pregnancy complications between exposed and unexposed groups. ${ }^{2}$ Wainstock et al. compared Israeli populations from two different cities (the first was subjected to constant rocket attacks, while the second was not exposed to those attacks) and found higher rates of preterm deliveries and low birthweight (less than 2,500 g) among the exposed women. 4 Although these studies found a correlation between low birth-weight and stress exposure, further analysis of these studies, and adjustment of their findings according to GA at birth, fails to show higher rates of IUGR among exposed women. In addition, the lack of uniformity between the study and the control groups, regarding background details and seasonality, might confound the results. ${ }^{12}$

Two other studies demonstrated that psychological stress during pregnancy was associated with an increased risk of stillbirth, preeclampsia, and elevated blood pressure, ${ }^{13,14}$ but neither of them had studied the effect of war-induced stress on pregnant women. Based on the HPA theory, the physiologic response to stress, which results in activation of the HPA axis, might lead to an increased blood glucose level. However, we were not able to show a higher rate of gestational diabetes among exposed women.

In our study, we compare the exposed population to women who lived in the same region and gave birth in the same calendar period of the year, and by that means we eliminated possible confounders, such as demographic details and season of the year. 
Pregnancy Complications and Mental Stress

The fact that we found no difference in pregnancy complication rates at all could be explained by two options: either by "too low a level of mental stress" caused by this military operation, or by the strong, rough, and durable personality of the Israeli civilians.

The literature about if and how to measure stress exposure objectively is controversial: while some studies used questionnaires or interviews in order to quantify the perceived level of stress, others defined the level of stress according to the extent of exposure, and did not evaluate the subjective stress level. ${ }^{15-19}$ Wainstock et al., who studied pregnancy complications among Israeli women who were constantly exposed to rocket attacks, found a significant correlation between the level of stress as assessed by questionnaires and the reported stress level associated with exposure to alarms. ${ }^{20}$ Based on this assertion, we can confidently assume that the studied population experienced different levels of stress.

This study has several strengths: it is one of the largest studies ever conducted about the association between prenatal mental stress and pregnancy complications among a population subjected to military attacks. In addition, despite the complexity in conducting this kind of study, the careful selection of the control group enabled us to isolate the studied parameters and to consider the effect of possible confounders as negligible. There are two limitations to this study: first, its retrospective design; second, the lack of a second control-i.e. women who conceived after the military operation and delivered during the following year.

In conclusion, exposure to military-induced mental stress during pregnancy, for a period of almost two months, has not been found to be associated with increased risk for pregnancy complications, regardless of the extent of stress or the gestational age at the time of exposure.

\section{REFERENCES}

1. Harville E, Xiong X, Buekens P. Disasters and perinatal health: a systematic review. Obstet Gynecol Surv 2010;65:713-28. Crossref

2. Maric NP, Dunjic B, Stojiljkovic DJ, Britvic D, Jasovic-Gasic M. Prenatal stress during the 1999 bombing associated with lower birth weight - a study of 3,815 births from Belgrade. Arch Womens Ment Health 2010;13:83-9. Crossref

3. Qiu C, Williams MA, Calderon-Margalit R, Cripe SM, Sorensen TK. Preeclampsia risk in relation to maternal mood and anxiety disorders diagnosed before or during early pregnancy. Am J Hypertens 2009;22:397-402. Crossref

4. Wainstock T, Anteby EY, Glasser S, Lerner-Geva L, Shoham-Vardi I. Exposure to life-threatening stressful situations and the risk of preterm birth and low birth weight. Int J Gynecol Obstet 2014;125:28-32. Crossref

5. Hosseini SM, Biglan MW, Larkby C, Brooks MM, Gorin MB, Day NL. Trait anxiety in pregnant women predicts offspring birth outcomes. Paediatr Perinat Epidemiol 2009;23:557-66. Crossref

6. Hobel CJ, Goldstein A, Barrett ES. Psychosocial stress and pregnancy outcome. Clin Obstet Gynecol 2008;51:333-48. Crossref

7. Bodalal Z, Agnaeber K, Nagelkerke N, Stirling B, Temmerman M, Degomme O. Pregnancy outcomes in Benghazi, Libya, before and during the armed conflict in 2011. East Mediterr Health J 2014;20:175-80.

8. Israel Defense Forces. Operation Protective Edge by numbers. Available at: http://bit.ly/2pcIqNm (accessed April 17, 2017).

9. Israel Ministry of Foreign Affairs. The 2014 Gaza Conflict: Factual and Legal Aspects. Available at: http://bit.ly/2pcM4He (accessed April 17, 2017).

10. Dutton MA, Greene R. Resilience and crime victimization. J Trauma Stress 2010;23:215-22. Crossref

11. Vest AR, Cho LS. Hypertension in pregnancy. Cardiol Clin 2012;30:407-23. Crossref

12. Lee SJ, Steer PJ, Filippi V. Seasonal patterns and preterm birth: a systematic review of the literature and an analysis in a London-based cohort. BJOG 2006;113:1280-8. Crossref

13. Wisborg K, Barklin A, Hedegaard M, Henriksen TB. Psychological stress during pregnancy and stillbirth: prospective study. BJOG 2008;115:882-5. Crossref

14. Kurki T, Hiilesmaa V, Raitasalo $R$, Mattila $H$, Ylikorkala O. Depression and anxiety in early pregnancy and risk for preeclampsia. Obstet Gynecol 2000;95:487-90. rossref

15. Zung A, Blumenfeld O, Shehadeh N, et al. Increase in the incidence of type 1 diabetes in Israeli children following the Second Lebanon War. Pediatr Diabetes 2012;13:326-33. Crossref

16. Hedegaard M, Henriksen TB, Secher NJ, Hatch MC, Sabroe S. Do stressful life events affect duration of gestation and risk of preterm delivery? Epidemiology 1996;7:339-45. $\underline{\text { Crossref }}$

17. Hedegaard M, Henriksen TB, Sabroe S, Secher NJ. Psychological distress in pregnancy and preterm delivery. BMJ 1993;307:234-9. $\underline{\text { Crossref }}$ 
18. Khashan AS, McNamee R, Abel KM, et al. Reduced infant birthweight consequent upon maternal exposure to severe life events. Psychosom Med 2008;70: 688-94. $\underline{\text { Crossref }}$

19. Copper RL, Goldenberg RL, Das A, et al. The preterm prediction study: maternal stress is associated with spontaneous preterm birth at less than thirty-five weeks' gestation. National Institute of Child Health and Human Development Maternal-Fetal Medicine Units Network. Am J Obstet Gynecol 1996;175:128692. Crossref

20. Wainstock T, Anteby E, Glasser S, Shoham-Vardi I, Lerner-Geva L. The association between prenatal maternal objective stress, perceived stress, preterm birth and low birthweight. J Matern neonatal Med 2013;26:973-7. $\underline{\text { Crossref }}$ 